\title{
Observation of temperature-dependent heavy- and light-hole split direct bandgap and tensile strain from $\mathrm{Ge}_{0.985} \mathrm{Sn}_{0.015}$ using photoreflectance spectroscopy
}

\section{Hyun-Jun Jo ${ }^{a}$, Geun Hyeong Kim ${ }^{\text {a }}$, Jong Su Kim ${ }^{\text {a,* }}$, Mee-Yi Ryu ${ }^{\text {b }}$, Yung Kee Yeo ${ }^{c}$, Thomas R Harris ${ }^{c, * *}$, John Kouvetakis ${ }^{d}$}

\author{
${ }^{\mathrm{a}}$ Department of Physics, Yeungnam University, Gyeongbuk 712-749, Republic of Korea \\ ${ }^{\mathrm{b}}$ Department of Physics, Kangwon National University, Kangwon-do 200-701, Republic of \\ Korea \\ ${ }^{\mathrm{c}}$ Department of Engineering Physics, Air Force Institute of Technology, Ohio 45433, USA \\ ${ }^{\mathrm{d}}$ Department of Chemistry and Biochemistry, Arizona State University, Arizona 85287, USA
}

Temperature- (T-) dependent photoreflectance (PR) measurements have been made for the tensile-strained, undoped $\mathrm{Ge}_{0.985} \mathrm{Sn}_{0.015}$ film grown on $n$-Si substrate by ultra-high vacuum chemical vapor deposition method. The PR spectra at room temperature consist of two signals at around 0.739 and $1.022 \mathrm{eV}$, which are assigned to the direct transitions from conduction $\Gamma$ valley to valence and spin-orbit split-off bands, respectively. The T-dependent PR measurements show tensile-strain split direct bandgap transitions from the $\Gamma$ valley to the light-hole $\left(\mathrm{E}_{\mathrm{LH}}\right)$ and heavy-hole $\left(\mathrm{E}_{\mathrm{HH}}\right)$ bands at energies of 0.772 and $0.803 \mathrm{eV}$ at $12 \mathrm{~K}$, respectively, which are not usually observable from the photoluminescence measurements for relatively high $\mathrm{Sn}$ content $\mathrm{Ge}_{1-\mathrm{y}} \mathrm{Sn}_{\mathrm{y}}$ samples. The PR signals for both $\mathrm{HH}$ and $\mathrm{LH}$ bands are blue shifted and their intensities decrease with increasing temperature, but both $\mathrm{LH}$ and $\mathrm{HH}$ PR signals persist through $240 \mathrm{~K}$ and only one HH PR signal is observed at room temperature. It has been observed that the separation energy between the $\mathrm{E}_{\mathrm{HH}}$ and $\mathrm{E}_{\mathrm{LH}}$ increases as $\mathrm{T}$ decreases, which clearly indicates an increase in tensile strain as $\mathrm{T}$ decreases. From the analysis of the T-dependent separation energy between the $\mathrm{E}_{\mathrm{LH}}$ and $\mathrm{E}_{\mathrm{HH}}$, the T-dependent tensile strain in the $\mathrm{Ge}_{0.985} \mathrm{Sn}_{0.015}$ film was obtained, which might not be easily measured using the X-ray diffraction method. 
**Present address: Air Force Research Laboratory, Wright-Patterson AFB, OH 45433

\section{Introduction}

Silicon has been used for its electronic device and integrated circuit applications for many decades, but it is a very poor light emitting source due to its indirect bandgap nature. Therefore, in recent decades, intensive research has been pursued to develop $\mathrm{Si}$ - and $\mathrm{Ge}$ based direct bandgap semiconductors such as $\mathrm{Ge}, \mathrm{Ge}_{1-\mathrm{y}} \mathrm{Sn}_{\mathrm{y}}$, and $\mathrm{Ge}_{1-\mathrm{x}-\mathrm{y}} \mathrm{Si}_{\mathrm{x}} \mathrm{Sn}_{\mathrm{y}}$ films grown on $\mathrm{Si}$ or Ge substrates to expand its functionalities well beyond electronics to possible new optoelectronic devices [1-8]. Many research groups have reported the photoluminescence (PL) results of the tensile strained $\mathrm{Ge}$ and $\mathrm{Ge}_{1-\mathrm{y}} \mathrm{Sn}_{\mathrm{y}}$ alloys [9-13], and the electroluminescence (EL) emissions of direct bandgap from various $\mathrm{Ge}-$ and $\mathrm{Ge}_{1-\mathrm{y}} \mathrm{Sn}_{\mathrm{y}}$-based diode structures [6,11]. In spite of the great recent progress in the crystal growth methods of $\mathrm{Ge}_{1-\mathrm{y}} \mathrm{Sn}_{\mathrm{y}}$ alloys on $\mathrm{Si}$ substrate, the as-grown alloys often required a post-growth annealing treatment to improve its crystallinity. However, the annealed $\mathrm{Ge}_{1-\mathrm{y}} \mathrm{Sn}_{\mathrm{y}} / \mathrm{Si}$ alloys could have a biaxial tensile strain upon cooling $[14,15]$.

An enhancement in PL intensity has been observed for the tensile strained Ge film in the near-infrared regime compared to bulk Ge due to the shrinkage of the direct bandgap $[16,17]$. In addition, tensile strain causes the splitting of light-hole (LH) and heavy-hole (HH) valence bands of $\mathrm{Ge}_{1-\mathrm{y}} \mathrm{Sn}_{\mathrm{y}}[12,18]$. Only a few researchers have reported the separation between $\mathrm{LH}$ and $\mathrm{HH}$ valence bands for the $\mathrm{Ge}$ and the $\mathrm{Ge}_{1-\mathrm{y}} \mathrm{Sn}_{\mathrm{y}}$ films at room temperature through photoreflectance (PR) spectroscopy so far $[12,18,19]$. Although the direct bandgap energies of strained $\mathrm{Ge}_{1-\mathrm{y}} \mathrm{Sn}_{\mathrm{y}}$ films grown on $\mathrm{Si}$ occurring between the conduction band $\Gamma$ valley and LH- and HH-valence bands could be calculated as a function of in-plane strain, the theoretical calculation of the tensile strain is difficult after the annealing process. In general, the strain is calculated by using rocking curves of a high resolution X-ray diffraction (HRXRD), but the measurements are difficult at low temperatures. Alternatively, Thomas et al. reported temperature dependent strain on a $\mathrm{ZnSe} / \mathrm{GaAs}$ using PR measurements [20]. Although several PR papers for the strained $\mathrm{Ge}_{1-\mathrm{y}} \mathrm{Sn}_{\mathrm{y}} / \mathrm{Si}$ alloys have been reported at room temperature, there have hardly been any reports on the temperature dependent tensile strain and separation energy between $\mathrm{HH}$ - and $\mathrm{LH}$-valence bands for the $\mathrm{Ge}_{1-\mathrm{y}} \mathrm{Sn}_{\mathrm{y}} / \mathrm{Si}$ alloys using 
the PR measurements. In this paper, the PR results of direct bandgap transition energies between $\Gamma$ conduction valley and $\mathrm{LH}-$ and $\mathrm{HH}$-valence bands in the biaxial tensile-strained $\mathrm{Ge}_{0.985} \mathrm{Sn}_{0.015} / \mathrm{Si}$ are reported as a function of sample temperature, as well as the calculated results of the temperature-dependent tensile strain from the energy separation between LH and $\mathrm{HH}$ optical transitions.

\section{Experiment}

The undoped $\mathrm{Ge}_{0.985} \mathrm{Sn}_{0.015}$ film was grown by using an ultra-high vacuum chemical vapor deposition method directly on $n$-type $\mathrm{Si}$ substrate with $\rho=0.005 \Omega$-cm via deuterated stannane $\left(\mathrm{SnD}_{4}\right)$ assisted reactions of pure digermane $\left(\mathrm{Ge}_{2} \mathrm{H}_{6}\right)$ at an optimum growth temperature of $375^{\circ} \mathrm{C}$ and at a pressure of 0.4 Torr. The content of $1.5 \% \mathrm{Sn}$ and a film thickness of $620 \mathrm{~nm}$ were estimated from Rutherford backscattering (RBS) measurements. The as-grown $\mathrm{Ge}_{0.985} \mathrm{Sn}_{0.015}$ film was annealed at $750{ }^{\circ} \mathrm{C}$ for $30 \mathrm{~min}$ in a hydrogen environment, which resulted in the improved crystallinity of the sample greatly as observed from the narrowing of the XRD peak (not shown here). Apparently, the annealing process reduces the levels of threading defects. The strain in the as-grown $\mathrm{Ge}_{0.985} \mathrm{Sn}_{0.015}$ epitaxial layer was initially slightly compressive. However, the sample became fully relaxed after the annealing treatment, and then changed to slightly tensile strain upon cooling to room temperature due to the large difference in thermal expansion coefficients between $\mathrm{Ge}_{0.985} \mathrm{Sn}_{0.015}$ and $\mathrm{Si}[21,22]$. The lattice constants were estimated using 224 reciprocal space maps measured by HRXRD, yielding $\mathrm{a}=5.6801 \AA$ and $\mathrm{c}=5.6583 \AA$. The latter is similar to the value $c=5.6587 \AA$ obtained from 004 on-axis peaks. The final residual tensile strain value was estimated to be $0.20 \%$ according to HRXRD measurement. More detailed descriptions of $\mathrm{Ge}_{1-\mathrm{y}} \mathrm{Sn}_{\mathrm{y}}$ crystal growth and annealing temperatures can be found from references [9] and [23], and those of RBS and HRXRD measurements can be obtained from references [23] and [24].

PR measurements were performed using a $637 \mathrm{~nm}$ laser diode as an excitation source with the excitation intensity of $400 \mathrm{~mW} / \mathrm{cm}^{2}$, and the PR signals were detected by an extended InGaAs detector $(1,000-2,400 \mathrm{~nm})$. The probe light was a monochromatic beam obtained from a tungsten-halogen lamp dispersed through a monochromator. PR spectra were 
measured at temperatures ranging from 12 to $300 \mathrm{~K}$. A more detailed description of the PR setup can be found in Ref. 25 .

\section{Results and discussion}

The PR spectra of undoped as-grown and annealed $\mathrm{Ge}_{0.985} \mathrm{Sn}_{0.015}$ films grown on $n$-Si substrate are shown in Fig. 1. The inset of the figure shows the PR spectrum of a p-type bulk Ge, which was used as a reference sample. The measurements were performed at $300 \mathrm{~K}$ with a laser excitation intensity of $400 \mathrm{~mW} / \mathrm{cm}^{2}$. The PR spectrum for the as-grown undoped $\mathrm{Ge}_{0.985} \mathrm{Sn}_{0.015}$ film exhibits a broad PR spectrum (black color), which may indicate slightly poor crystal quality for this film. On the other hand, the PR spectrum of the thermally annealed $\mathrm{Ge}_{0.985} \mathrm{Sn}_{0.015}$ film (red color) shows very clear and specific features of spectrum. This result indicates that the crystal quality of the $\mathrm{Ge}_{0.985} \mathrm{Sn}_{0.015}$ film improves greatly after thermal annealing. These PR observations agree with the fact that in general, the PR spectra of doped or poor quality semiconductors are broad, and the PR spectra of undoped, good quality semiconductors show sharp and specific features.

The PR spectrum of annealed $\mathrm{Ge}_{0.985} \mathrm{Sn}_{0.015} / n$-Si is mainly composed of two transition signals located at around 0.75 and $1.03 \mathrm{eV}$. For the bulk Ge sample, the direct bandgap transition PR signal was obtained at around $0.80 \mathrm{eV}$ as shown in the inset of Fig. 1, which is in good agreement with the direct transition energy $\left(E_{D}\right)$ of the Ge [26]. Also, the direct transition from the $\Gamma$ valley in conduction band to the spin-orbit split-off band $\left(E_{S O}\right)$ was observed approximately at $1.09 \mathrm{eV}$ for this bulk Ge sample. In light of the positions of the $E_{D}$ and $E_{S O}$ transition signals for the bulk Ge sample, the PR signals at around 0.75 and $1.03 \mathrm{eV}$ obtained from the undoped annealed $\mathrm{Ge}_{0.985} \mathrm{Sn}_{0.015}$ film are attributed to the direct bandgap transition and the spin-orbit split-off band transition, respectively. The smaller direct bandgap transition energy of the undoped $\mathrm{Ge}_{0.985} \mathrm{Sn}_{0.015}$ sample $\left(E_{D} \approx 0.75 \mathrm{eV}\right)$ compared to the bulk Ge sample $\left(E_{D} \approx 0.8 \mathrm{eV}\right)$ is attributed to the $1.5 \%$ Sn concentration and $0.20 \%$ tensile strain induced by the thermal expansion mismatch between $\mathrm{Ge}_{0.985} \mathrm{Sn}_{0.015}$ and $\mathrm{Si}$ substrate during cooling to room temperature. These direct transitions for $\mathrm{Ge}$ and various $\mathrm{Ge}_{1-\mathrm{y}} \mathrm{Sn}_{\mathrm{y}}$ alloys have also been reported by several groups [14,15,27-31]. It is also worthwhile to point out that, the indirect bandgap related PR signal was not observed either from the bulk Ge or the annealed $\mathrm{Ge}_{0.985} \mathrm{Sn}_{0.015} / n-\mathrm{Si}$ samples. In the case of indirect bandgap semiconductors, the PR signal is 
usually dominated by signals from the direct bandgap transition because of relatively inefficient indirect bandgap related re-emission. Therefore, it is often difficult to observe any PR spectrum related to the indirect transition.

In order to determine the direct bandgap transition energy of $E_{D}$, the third-derivative of Lorentzian form was used to analyze the line shape of PR signal. Under low electric field condition, the line shape of the PR spectrum is given by [32]

$$
\frac{\Delta R}{R}=\sum_{j=1}^{n} \operatorname{Re}\left[C_{j} e^{i \varphi_{j}}\left(E-E_{j}+i \Gamma_{j}\right)^{-m}\right]
$$

where $C_{j}$ and $\varphi_{j}$ are amplitude and phase factors, respectively. $E_{j}$ is the transition energy, $E$ is the photon energy, $\Gamma_{j}$ is the broadening parameter, and $\mathrm{m}$ is the line-shape factor. The factor $\mathrm{m}$ is chosen to be 2.5 , which represents a three-dimensional critical point. The calculated $E_{D}$ and $E_{S O}$ are 0.739 and $1.022 \mathrm{eV}$, respectively. At room temperature, the $E_{D}$ between the conduction $\Gamma$ valley and the valence band for unstrained $\mathrm{Ge}_{1-\mathrm{x}} \mathrm{Sn}_{\mathrm{x}}$ is given as a function of Sn concentration by the following equation [33].

$$
E_{g}\left(G e_{1-x} S n_{x}\right)=(1-\mathrm{x}) E_{g}(G e)+x E_{g}(S n)-b x(1-x)
$$

where the direct transition energies of $\mathrm{Ge}$ and $\mathrm{Sn}$ are 0.80 and $-0.41 \mathrm{eV}$, respectively, and the bowing parameter $\mathrm{b}$ used is $2.42 \mathrm{eV}$ [33]. The calculated direct transition energy of $\mathrm{Ge}_{0.985} \mathrm{Sn}_{0.015}$ film from Eq. (2) is approximately $0.746 \mathrm{eV}$. The $E_{D}(0.739 \mathrm{eV})$ obtained from Eq. (1) is slightly lower than that from Eq. (2) due to the presence of biaxial tensile strain $(0.20 \%)$.

Temperature-dependent PR measurement was performed for the annealed $\mathrm{Ge}_{0.985} \mathrm{Sn}_{0.015}$ film and the results are shown in Fig. 2. The $E_{D}$ and $E_{S O}$ positions are blue-shifted as temperature decreases from room temperature due to increases in direct bandgap and spinorbit split-off band energies by lattice shrinkage. More importantly, the weaker signal below the dominant PR signal is gradually separated from the main signal and the weaker signal becomes much more distinct as temperature deceases further to low temperatures as shown in the figure. The two PR signals (e.g., 0.772 and $0.803 \mathrm{eV}$ at $12 \mathrm{~K}$ ) are attributed to the direct bandgap energy transitions from the conduction $\Gamma$ valley to the $\mathrm{LH}$ and $\mathrm{HH}$ valence bands. In 
case of thin film under biaxial tensile strain, the degeneracy of LH and HH bands is broken, and the separation energy between the $\mathrm{LH}$ and $\mathrm{HH}$ bands increases as the tensile strain increases due to increased thermal expansion mismatch with decreasing temperature [15]. This is clearly shown in Fig. 2(a) for the tensile strained $\mathrm{Ge}_{0.985} \mathrm{Sn}_{0.015}$ sample as marked in arrows, where the direct bandgap transition signal for the LH band occurs at lower energy than that for the $\mathrm{HH}$ band. However, the transition signal to the $\mathrm{LH}$ band is observed at a higher energy than that to the $\mathrm{HH}$ band for the compressively strained $\mathrm{Ge}_{1-\mathrm{y}} \mathrm{Sn}_{\mathrm{y}}$ sample [33]. This observation of clear separation between the LH and HH bands through the T-dependent PR measurements are particularly note worthy for this $1.5 \%$ Sn content sample because the separation of LH and HH peaks was not observed by PL measurements. In general, the separation of LH and HH PL peaks are hardly observed by PL method even for a relatively higher Sn content sample. For example, the observation of the separated LH and HH PL peaks were reported from the tensile-strained GeSn with only $0.03 \% \mathrm{Sn}$ content at below the room temperature [15]. The photoreflection consists of both absorption and re-emission and the amplitude of the PR signal depends on the number of density states. Therefore, the PR signal of the HH band is much stronger than that of the LH band due to the higher density of states in the HH band. It is observed that the PR signals for both $\mathrm{HH}$ and LH bands decrease with increasing temperature. The split of LH and HH PR signals persists through $240 \mathrm{~K}$ and only one PR signal for $\mathrm{HH}$ band is observed at room temperature.

Temperature-dependence of the direct bandgap transition energies from the conduction $\Gamma$ valley to the $\mathrm{LH}\left(\mathrm{E}_{\mathrm{LH}}\right)$ and $\mathrm{HH}\left(\mathrm{E}_{\mathrm{HH}}\right)$ bands of $\mathrm{Ge}_{0.985} \mathrm{Sn}_{0.015}$ thin film are calculated from the analysis of the line shape of PR signal by Eq. (1), and the results are plotted in Fig. 2(b). Also, the energy separation between the $E_{\mathrm{HH}}$ and $E_{\mathrm{LH}}$ is plotted in the inset of Fig. 2(b) as a function of temperature. It is clearly seen in the figure that both the $\mathrm{E}_{\mathrm{LH}}$ and $\mathrm{E}_{\mathrm{HH}}(0.772$ and $0.803 \mathrm{eV}$, respectively, at $12 \mathrm{~K}$ ) decrease with increasing temperature due to bandgap shrinkage and decrease in tensile strain of the film. Also, the energy separation $(\sim 30 \mathrm{meV}$ at $12 \mathrm{~K})$ between the $\mathrm{E}_{\mathrm{HH}}$ and $\mathrm{E}_{\mathrm{LH}}$ decreases as temperature increases to room temperature $(\sim 21$ $\mathrm{meV}$ at $240 \mathrm{~K}$ ) due to decreasing tensile strain as shown in the inset of Fig. 2(b). This observation is consistent with the PL results observed from $0.03 \% \mathrm{Sn}$ GeSn sample [15]. The data for the HH and LH transition energies in Fig. 2(b) are well fitted with Varshni's type equation [34] 


$$
E_{D}(\mathrm{~T})=E_{D}(0)-\frac{\alpha T^{2}}{T+\beta}
$$

where $\alpha$ and $\beta$ are fitting constants of a given material. The fitting parameters used for the fitting curve are listed in Table I. The $\alpha$ and $\beta$ fitting values are slightly different from those of the bulk Ge due to the strain and Sn content of the $\mathrm{Ge}_{0.985} \mathrm{Sn}_{0.015}$ thin film.

According to deformation potential theory, the $\mathrm{E}_{\mathrm{LH}}$ and $\mathrm{E}_{\mathrm{HH}}$ are given by the following two equations [18]:

$$
\begin{aligned}
& E_{L H}=E_{g}^{\Gamma}(0)+a\left(\varepsilon_{\perp}+2 \varepsilon_{\|}\right)+\frac{\Delta_{0}}{2}-\frac{1}{4} \delta E_{100}-\frac{1}{2} \sqrt{\Delta_{0}^{2}+\Delta_{0} \delta E_{100}+\frac{9}{4}\left(\delta E_{100}\right)^{2}} \\
& E_{H H}=E_{g}^{\Gamma}(0)+a\left(\varepsilon_{\perp}+2 \varepsilon_{\|}\right)+\frac{1}{2} \delta E_{100} \\
& \delta E_{100}=2 b\left(\varepsilon_{\perp}-\varepsilon_{\|}\right)
\end{aligned}
$$

where $E_{L H}$ and $E_{H H}$ are the direct transition energies from the bottom of the conduction $\Gamma$ valley to the top of the $\mathrm{LH}$ and $\mathrm{HH}$ valence bands under an in-plane strain $\left(\varepsilon_{\|}\right)$, respectively, and $\varepsilon_{\perp}$ is the perpendicular strain to the film. $E_{g}^{\Gamma}(0)$ is the direct transition energy of unstrained bulk Ge at room temperature. $\Delta_{0}$ is the energy separation from the top of the valence band to the spin-orbit split-off band. $a$ and $b$ are deformation potential constants at room temperature. The above relations clearly show that the $\mathrm{E}_{\mathrm{LH}}$ and $\mathrm{E}_{\mathrm{HH}}$ depend on both the strain and the elastic constants in the $\mathrm{Ge}_{0.985} \mathrm{Sn}_{0.015}$ film and conversely, strain depends on the $\mathrm{E}_{\mathrm{LH}}$ and $\mathrm{E}_{\mathrm{HH}}$, all of which are also temperature dependent. The difference between the $\mathrm{E}_{\mathrm{HH}}$ and $\mathrm{E}_{\mathrm{LH}}$ is given by

$$
\Delta E=E_{H H}-E_{L H}=-\frac{\Delta_{0}}{2}+\frac{3}{4} \delta E_{100}+\frac{1}{2} \sqrt{\Delta_{0}^{2}+\Delta_{0} \delta E_{100}+\frac{9}{4}\left(\delta E_{100}\right)^{2}}
$$

where $\delta E_{100}=2 b\left(\varepsilon_{\perp}-\varepsilon_{\|}\right)$as shown in Eq. (4c). Using this equation, the strain can be calculated from the estimated separation energy of $\left(E_{\mathrm{HH}}-E_{\mathrm{LH}}\right)$, which was calculated from the analysis of the line shape of the measured PR signals. A value of $0.276 \mathrm{eV}$ was used for 
$\Delta_{0}$, which was obtained from the energy difference between the $\mathrm{E}_{\mathrm{SO}}(1.022 \mathrm{eV}$ from Eq. (1)) and $E_{g}\left(G e_{1-x} S n_{x}\right)(0.746 \mathrm{eV}$ from Eq. (2)) for the unstrained film. In the calculation, the bulk Ge values of $\varepsilon_{\|} / \varepsilon_{\perp}=-1.33$ [18] and $b=-2.55 \mathrm{eV}$ [36], which are assumed to be independent of the temperature, were used as a good approximation for current sample. The calculated results for the temperature-dependent tensile strains using the measured separation energy of $\left(E_{\mathrm{HH}}-\mathrm{E}_{\mathrm{LH}}\right)$ from PR signals are plotted in Fig. 3. The tensile strain $(\sim 0.32 \%$ at 12 $\mathrm{K})$ decreases with increasing temperature as reflected from the decreased splitting of the $\mathrm{LH}$ and $\mathrm{HH}$ bands. In addition, tensile strain values were theoretically calculated using the Tdependent thermal expansivities of bulk $\mathrm{Ge}$ and $\mathrm{Si}$, and the results are plotted as a solid (red) line in Fig. 3. The calculation assumed a room temperature strain value of $0.20 \%$ which was estimated from the HRXRD measurements for this sample. As seen in the figure, the tensile strain determined from the PR results is slightly larger than the theoretical values, however the overall trend agrees well. It is important to point out that the temperature-dependent tensile strain of $\mathrm{Ge}_{1-\mathrm{x}} \mathrm{Sn}_{\mathrm{x}}$ could be estimated through the PR measurements as this paper indicates. More accurate estimation can be obtained from the accurate measurement of separation energy between the $\mathrm{E}_{\mathrm{HH}}$ and $\mathrm{E}_{\mathrm{LH}}$ values, and from the accurately known physical parameters of $\mathrm{Ge}_{1-\mathrm{x}} \mathrm{Sn}_{\mathrm{x}}$ including accurate deformation potential.

\section{Conclusion}

The temperature-dependent heavy- and light-hole direct bandgap energies and tensile strain of undoped $\mathrm{Ge}_{0.985} \mathrm{Sn}_{0.015}$ film grown on $n$-Si substrate have been investigated by using photoreflectance (PR) spectroscopy measurements. The PR spectrum for the as-grown $\mathrm{Ge}_{0.985} \mathrm{Sn}_{0.015}$ film exhibits a broad spectrum, whereas that for the thermally annealed film shows very clear and specific features of spectrum, indicating a great improvement of the crystal quality of the film after thermal annealing at $750^{\circ} \mathrm{C}$ for $30 \mathrm{~min}$. The annealed $\mathrm{Ge}_{0.985} \mathrm{Sn}_{0.015}$ film shows two optical transition signals at around 0.739 and $1.022 \mathrm{eV}$ at $300 \mathrm{~K}$, which are assigned to the direct transition energies from the conduction $\Gamma$ valley to heavyhole $(\mathrm{HH})$ valence and spin-orbit $(\mathrm{SO})$ split-off $\left(\mathrm{E}_{\mathrm{SO}}\right)$ bands, respectively. The direct transition energy positions determined from the analysis of the line shape of PR signal are blue-shifted as the temperature decreases due to increase in direct bandgap and SO split-off 
band energies by lattice shrinkage. Also, two PR signals of tensile strain-split direct bandgap transitions (e.g., 0.772 and $0.803 \mathrm{eV}$ at $12 \mathrm{~K}$ ) are observed at low temperatures, and they are attributed to transition energies from the $\Gamma$ valley to the light-hole $(\mathrm{LH}), \mathrm{E}_{\mathrm{LH}}$, and heavy-hole bands, $\mathrm{E}_{\mathrm{HH}}$, where the energy value of $\mathrm{E}_{\mathrm{LH}}$ is lower than that of $\mathrm{E}_{\mathrm{HH}}$. The PR signal of the $\mathrm{HH}$ valence band is much stronger than that of the LH band due to the higher density of states in the HH band. The evolution of the T-dependent PR results clearly shows that the separation energy between the LH and $\mathrm{HH}$ bands increases gradually (e.g., from $\sim 21 \mathrm{meV}$ at $240 \mathrm{~K}$ to $\sim 30 \mathrm{meV}$ at $12 \mathrm{~K}$ ) as the tensile strain increases due to increased thermal expansion mismatch with decreasing temperature. This HH and LH valence band split is not usually observable from the PL measurements even for relatively high $\mathrm{Sn}$ content $\mathrm{Ge}_{1-\mathrm{y}} \mathrm{Sn}_{\mathrm{y}}$ samples. The PR signal intensities for both $\mathrm{HH}$ and $\mathrm{LH}$ bands decrease with increasing temperature, persist through $240 \mathrm{~K}$, and only the strong HH PR signal is observed at room temperature. The Tdependent tensile strain in the $\mathrm{Ge}_{0.985} \mathrm{Sn}_{0.015}$ film was obtained by analyzing the T-dependent separation energy between the $\mathrm{E}_{\mathrm{LH}}$ and $\mathrm{E}_{\mathrm{HH}}$. The obtained values agree well with the theory and with the room temperature value of $0.20 \%$ estimated from the HRXRD measurements. It is important to point out that the T-dependent tensile strain of GeSn could be relatively accurately estimated through the PR measurements instead of the XRD method.

\section{Acknowledgments}

This work was partially supported by the 2014 Yeungnam University Research Grant. This work was supported in part by a National Research Foundation of Korea grant funded by the Korean Government (NRF-2011-00111728 and NRF-2013K2A2A2000881). This research (MYR) was also supported in part by Basic Science Research Program through the National Research Foundation of Korea (NRF) funded by the Ministry of Education, Science and Technology (NRF-2013R1A1A2A10058310). The work at ASU was supported by US Air Force Office of Scientific Research (AFOSR) FA9550-12-1-0208. The authors (YKY and MYR) would like to express their sincere appreciation to Dr. Gernot S. Pomrenke of the AFOSR for his support of this work.

The views expressed in this article are those of the authors and do not reflect the official policy or position of the United States Air Force, Department of Defense, or the United States 
Government. 


\section{References}

[1] R. A. Soref, C. H. Perry, J. Appl. Phys. 69 (1991) 539.

[2] Y. Maeda, N. Tsukamoto, Y. Yazawa, Y. Kanemitsu, Y. Masumoto, Appl. Phys. Lett. 59 (1991) 3168 .

[3] Y. Nakamura, K. Watanabe, Y. Fukuzawa, M. Ichikawa, Appl. Phys. Lett. 87 (2005) 133119.

[4] C. Xu, L. Jiang, J. Kouvetakis, J. Menendez, Appl. Phys. Lett. 103 (2013) 072111.

[5] Y. Nakamura, A. Masada, M. Ichikawa, Appl. Phys. Lett. 91 (2007) 013109.

[6] J. P. Gupta, N. Bhargava, S. Kim, T. Adam, J. Kolodzey, Appl. Phys. Lett. 102 (2013) 251117.

[7] R. E. Camacho-Aguilera, Y. Cai, N. Patel, J. T. Bessette, M. Romagnoli, L. C. Kimerling, J. Michel, Opt. Express 20 (2012) 11316.

[8] M. Oehme, M. Schmid, M. Kaschel, M. Gollhofer, D. Widmann, E. Kasper, J. Schulze, Appl. Phys. Lett. 101 (2012) 141110.

[9] J. Mathews, R. T. Beeler, J. Tolle, C. Xu, R. Roucka, J. Kouvetakis, J. Menéndez, Appl. Phys. Lett. 97 (2010) 221912.

[10] M.-Y. Ryu, T. R. Harris, Y. K. Yeo, R. T. Beeler, J. Kouvetakis, Appl. Phys. Lett. 102 (2013) 171908.

[11] S.-L. Cheng, J. Lu, G. Shambat, H.-Y. Yu, K. Saraswat, J. Vuckovic, Y. Nishi, Opt. Express 17 (2009) 10019.

[12] Y. Ishikawa, K. Wada, J. Liu, D. D. Cannon, H.-C. Luan, J. Michel, L. C. Kimerling, J. Appl. Phys. 98 (2005) 013501.

[13] R. Jakomin, M. de Kersauson, M. El Kurdi, L. Largeau, O. Mauguin, G. Beaudoin, S. Sauvage, R. Ossikovski, G. Ndong, M. Chaigneau, I. Sagnes, P. Boucaud, Appl. Phys. Lett. 98 (2011) 091901.

[14] D. D. Cannon, J. Liu, Y. Ishikawa, K. Wada, D. T. Danielson, S. Jongthammanurak, J. 
Michel, L. C. Kimerling, Appl. Phys. Lett. 84 (2004) 906.

[15] T. R. Harris, Y. K. Yeo, M.-Y. Ryu, R. T. Beeler, J. Kouvetakis, J. Appl. Phys. 116 (2014) 103502.

[16] Y. Huo, H. Lin, R. Chen, M. Makarova, Y. Rong, M. Li, T. I. Kamins, J. Vuckovic, J. S. Harris, Appl. Phys. Lett. 98 (2011) 011111.

[17] T. H. Cheng, K. L. Peng, C. Y. Ko, C. Y. Chen, H. S. Lan, Y. R. Wu, C. W. Liu, H. H. Tseng, Appl. Phys. Lett. 96 (2010) 211108.

[18] J. Liu, D. D. Cannon, K. Wada, Y. Ishikawa, D. T. Danielson, S. Jongthammanurak, J. Michel, L. C. Kimerling, Phys. Rev. B 70 (2004) 155309.

[19] R. Roucka, J. Mathews, V. R. D’Costa, J. Xie, J. Tolle, S.-Q. Yu, J. Menendez, J. Kouvetakis, J. Vac. Sci. Technol. B 26 (2008) 1952.

[20] R. J. Thomas, B. Rockwell, H. R. Chandrasekhar, M. Chandrasekhar, A. K. Ramdas, M. Kobayashi, R. L. Gunshor, J. Appl. Phys. 78 (1995) 6569.

[21] V. R. D’Costa, Y. Fang, J. Mathews, R. Roucka, J. Tolle, J. Menéndez, J. Kouvetakis, Semicond. Sci. Technol. 24 (2009) 115006.

[22] R. Roucka, R. Beeler, J. Mathews, M.-Y. Ryu, Y. K. Yeo, J. Menéndez, J. Kouvetakis, J. Appl. Phys. 109 (2011) 103115.

[23] G. Grzybowski, R. T. Beeler, L. Jiang, D. J. Smith, J. Kouvetakis, J. Menendez, Appl. Phys. Lett. 101, (2012) 072105.

[24] H.-J. Jo, M. G. So, J. S. Kim, M.-Y. Ryu, Y. K. Yeo, J. Kouvetakis, Thin Solid Films 591 (2015) 295.

[25] J. S. Kim, P. W. Yu, S. K. Noh, J. I. Lee, J. S. Kim, S. M. Kim, G. H. Kim, S-K. Kang, S. G. Kim, J. S. Son, J. Y. Leem, J. Korean Phys. Soc. 39 (2001) 246.

[26] O. Madelung, Data in Science and Technology: Semiconductors Other Than Group IV Elements and III-V Compounds, Springer-Verlag, Berlin, 1992.

[27] V. R. D’Costa, C. S. Cook, A. G. Birdwell, C. L. Littler, M. Canonico, S. Zollner, J. Kouvetakis, J. Menendez, Phys. Rev. B 73 (2006) 125207. 
[28] S. Gupta, B. Magyari-Köpe, Y. Nishi, K. C. Saraswat, J. Appl. Phys. 113 (2013) 073707.

[29] J. D. Gallagher, C. L. Senaratne, J. Kouvetakis, J. Menéndez, Appl. Phys. Lett. 105 (2014) 142102.

[30] L. Jiang, J. D. Gallagher, C. L. Senaratne, T. Aoki, J. Mattews, J. Kouvetakis, J. Menéndez, Semicond. Sci. Technol. 29 (2014) 115028.

[31] S. A. Ghetmiri, W. Du, J. Margetis, A. Mosleh, L. Cousar, B. R. Conley, L. Domulevicz, A. Nazzal, G. Sun, R. A. Soref, J. Tolle, B. Li, H. A. Naseem, S.-Q. Yu, Appl. Phys. Lett. 105 (2014) 151109.

[32] D. E. Aspnes, A. A. Studna, Phys. Rev. B 7 (1973) 4605.

[33] H. Lin, R. Chen, W. Lu, Y. Huo, T. I. Kamins, J. S. Harris, Appl. Phys. Lett. 100 (2012) 102109.

[34] Y. P. Varshni, Physica 34 (1967) 149.

[35] M. E. Levinshten, S. L. Rumyantsev, M. Shur, Handbook Series on Semiconductor Parameters, Volume 1: Si, Ge, C (Diamond), GaAs, GaP, GaSb, InAs, InP, InSb (World Scientific, London, 1996).

[36] C. G. Van de Walle, Phys. Rev. B 39 (1989) 1871. 


\section{Table}

Table 1. Calculated results of $\mathrm{Ge}_{0.985} \mathrm{Sn}_{0.015}$ thin film using Varshni equation.

\section{Figure caption}

Fig. 1. Photoreflectance spectra of as-grown and annealed $\mathrm{Ge}_{0.985} \mathrm{Sn}_{0.015} / \mathrm{Si}$ thin films measured at room temperature. The inset is the PR spectrum of a bulk Ge.

Fig. 2. (a) Temperature-dependent photoreflectance spectra of the $\mathrm{Ge}_{0.985} \mathrm{Sn}_{0.015} / \mathrm{Si}$ thin film, showing heavy-hole, light-hole and split-off band direct bandgap transitions. (b) Light- $\left(\mathrm{E}_{\mathrm{LH}}\right)$ and heavy-hole $\left(\mathrm{E}_{\mathrm{HH}}\right)$ direct bandgap transition energies obtained from PR spectra are plotted as a function of temperature from 12 to $300 \mathrm{~K}$. The fitting curves are calculated using Varshni's type equation. The energy difference between the $\mathrm{E}_{\mathrm{HH}}$ and $\mathrm{E}_{\mathrm{LH}}$ is plotted in the inset. Fig. 3. Temperature-dependence of the tensile strain obtained by analyzing the separation between the $\mathrm{E}_{\mathrm{LH}}$ and the $\mathrm{E}_{\mathrm{HH}}$. The red line represents the theoretically calculated values. 
Table 1. Calculated results of $\mathrm{Ge}_{0.985} \mathrm{Sn}_{0.015}$ thin film using Varshni equation.

\begin{tabular}{|c|c|c|c|}
\hline & $\mathrm{E}(0)[\mathrm{eV}]$ & $\alpha\left[10^{-4} \mathrm{eV} / \mathrm{K}\right]$ & $\beta[\mathrm{K}]$ \\
\hline Direct bandgap of bulk Ge [35] & 0.853 & 5.82 & 296 \\
\hline Heavy-hole $\left(\mathrm{E}_{\mathrm{HH}}\right)$ & 0.804 & 4.20 & 284 \\
\hline Lighy-hole $\left(\mathrm{E}_{\mathrm{LH}}\right)$ & 0.774 & 2.95 & 237 \\
\hline Split-off band $\left(\mathrm{E}_{\mathrm{SO}}\right)$ & 1.086 & 4.43 & 327 \\
\hline
\end{tabular}




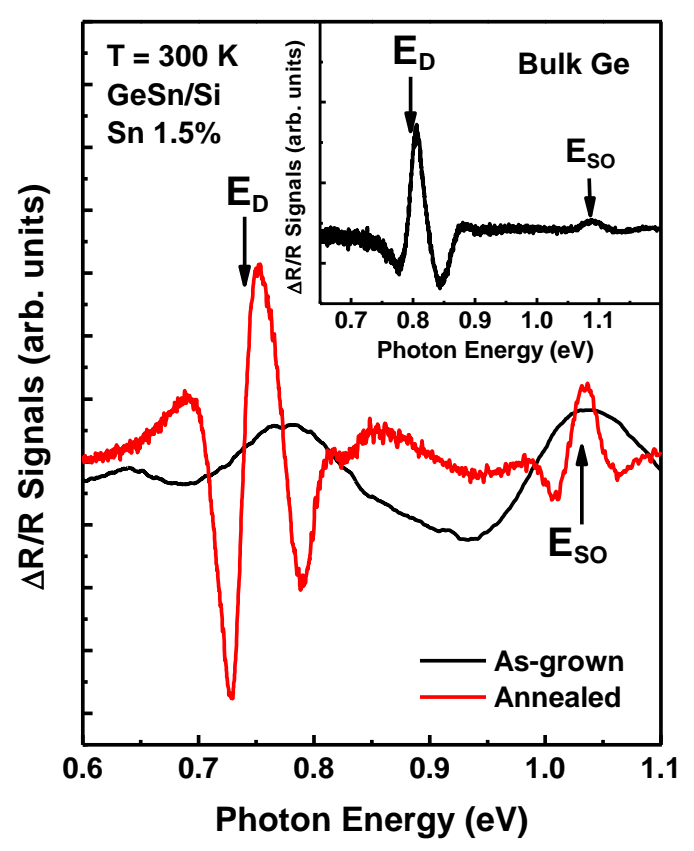

Fig. 1.
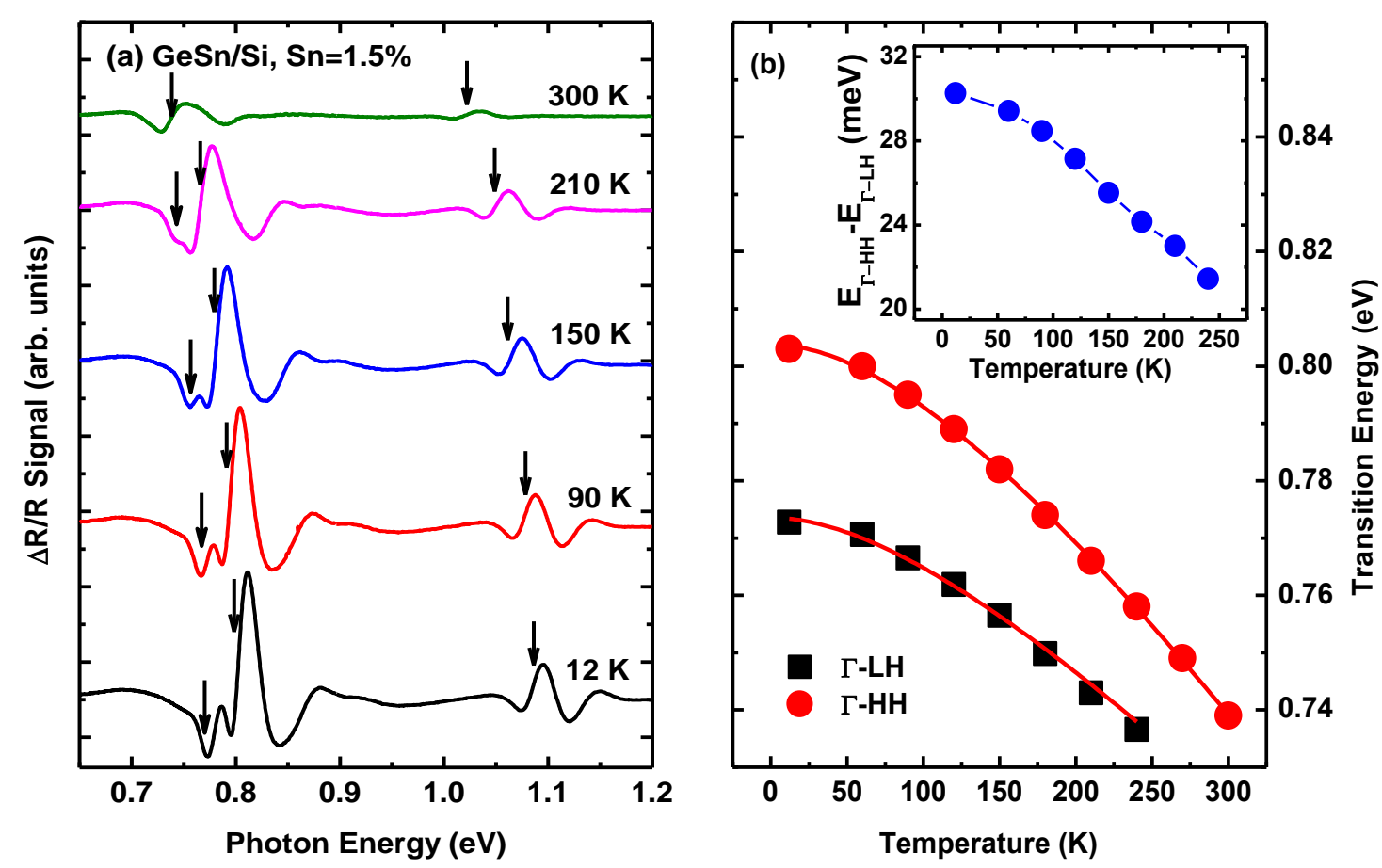

Fig. 2. 


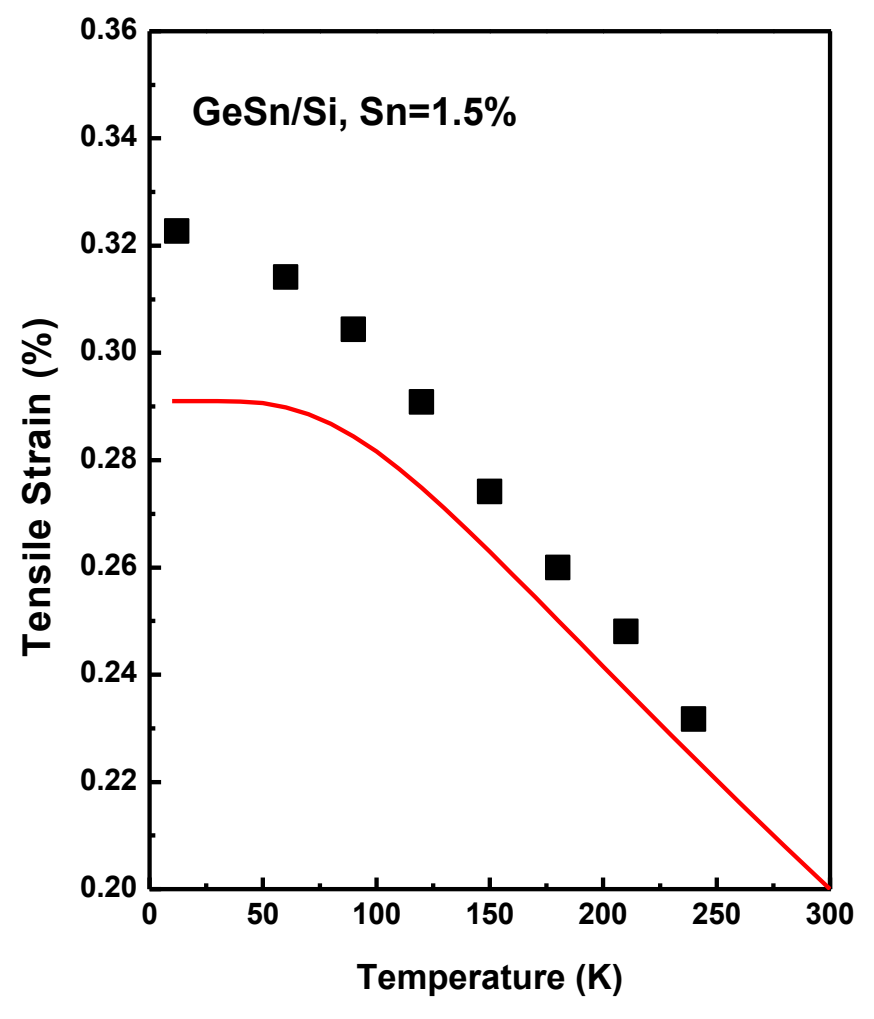

Fig. 3. 